\title{
The impact of flipped learning in surgical education: A
} mixed-method study

\section{Hossein Akbarialiabad}

Shiraz University of Medical Sciences and Health Services, Shiraz, Iran

Shiraz University of Medical Sciences, Shiraz, Iran

Nahid Zarifsanaiey

Mohammad Hossein Taghrir

Shiraz University of Medical Sciences, Shiraz, Iran

Sima Roushenas

Seyed Mehdi Panahandeh

Shiraz University of Medical Sciences and Health Services, Shiraz, Iran

Hossein Abdolrahimzadeh-fard

Zahra Shayan

Shiraz University of Medical Sciences, Shiraz, Iran

Shahin Kavousi

Shiraz University of Medical Sciences and Health Services, Shiraz, Iran

Shahram Paydar

Shiraz University of Medical Sciences, Shiraz, Iran

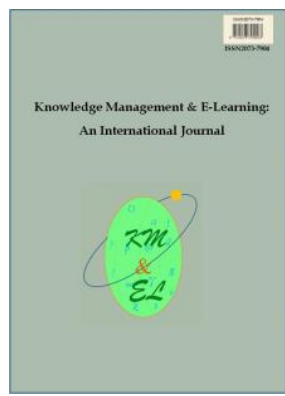

Knowledge Management \& E-Learning: An International Journal (KM\&EL)

ISSN 2073-7904

\section{Recommended citation:}

Akbarialiabad, H., Zarifsanaiey, N., Taghrir, M. H., Roushenas, S., Panahandeh, S. M., Abdolrahimzadeh-fard, H., Shayan, Z., Kavousi, S., \& Paydar, S. (2021). The impact of flipped learning in surgical education: A mixed-method study. Knowledge Management \& E-Learning, 13(3), 273289. https://doi.org/10.34105/j.kmel.2021.13.015 


\section{The impact of flipped learning in surgical education: A mixed-method study}

\section{Hossein Akbarialiabad*}

Student Research Committee, School of Medicine Shiraz University of Medical Sciences and Health Services, Shiraz, Iran Research Center for Psychiatry and Behavioral Sciences Department of Psychiatry, School of Medicine Shiraz University of Medical Sciences, Shiraz, Iran

E-mail: hosseinakbari7575@gmail.com

\section{Nahid Zarifsanaiey}

Department of E-Learning

Center of Excellence for E-Learning in Medical Sciences, Virtual School Shiraz University of Medical Sciences, Shiraz, Iran

E-mail: nzarifsanaee@gmail.com

\section{Mohammad Hossein Taghrir}

Trauma Research Center, Rajaee (Emtiaz) Trauma Hospital Shiraz University of Medical Sciences, Shiraz, Iran

E-mail: mhtaghrir@gmail.com

\section{Sima Roushenas}

Student Research Committee, School of Medicine

Shiraz University of Medical Sciences and Health Services, Shiraz, Iran E-mail: sima.rooshenas@gmail.com

\section{Seyed Mehdi Panahandeh}

Student Research Committee, School of Medicine

Shiraz University of Medical Sciences and Health Services, Shiraz, Iran

E-mail: mehdipanahandeh@gmail.com

\section{Hossein Abdolrahimzadeh-fard*}

Trauma Research Center, Rajaee (Emtiaz) Trauma Hospital Shiraz University of Medical Sciences, Shiraz, Iran

E-mail: Dr.h.a.fard@gmail.com 


\title{
Zahra Shayan
}

Trauma Research Center, Department of Biostatistics

School of Medicine

Shiraz University of Medical Sciences, Shiraz, Iran

E-mail: shayanz@sums.ac.ir

\section{Shahin Kavousi}

Student Research Committee, School of Medicine

Shiraz University of Medical Sciences and Health Services, Shiraz, Iran

E-mail: shahinkavousi@gmail.com

\section{Shahram Paydar*}

Trauma Research Center, Rajaee (Emtiaz) Trauma Hospital

Shiraz University of Medical Sciences, Shiraz, Iran

E-mail: Paydarsh@gmail.com

*Corresponding author

\begin{abstract}
This study aims to investigate the effectiveness of flipped learning in surgical education in trauma. The participants were 15 first-year general surgery residents in Shiraz medical school. After completing a pre-test, the participants received the learning content in interactive multimedia, podcasts, movies, and books. One month later, they had a face-to-face class based on case-based discussions. An early post-test was performed immediately after the class, and a late post-test was performed one month later. In these tests, the residents' problem-solving abilities were assessed using multiple-choice questions. A semi-structured phone interview was used to measure their attitude towards the learning program. The results showed a significant difference between pre-test and early post-test scores and between pre-test and late post-test scores. However, there was no significant difference between early and late post-test scores. The residents were satisfied with the program's overall usefulness for junior residents. The participants tended to use podcasts more than other materials. They mentioned that the videos and books helped more to foster theoretical knowledge. The case-based discussion makes them more confident in dealing with patients in daily encounters.
\end{abstract}

Keywords: Medical education; Surgical education; Trauma; Blended learning; Flipped education

Biographical notes: Dr. Hossein Akbarialiabad is a recently M.D.M.S. (medical education) graduated alumnus of Shiraz University of Medical Sciences, Shiraz, Iran. Currently, he is based in Zimbabwe to cooperating in relevant global health research. He has been involved in multiple disciplinary research in the areas of cognitional neurosciences, global mental health, mentorship in medical education, complex problem solving and learning, digital health, including digital phenotyping and digital phenotyping, and artificial intelligence. He has been co-author of four books and multiple papers in various reputable journals. More details can be found at https://www.researchgate.net/profile/Hossein-Akbarialiabad 
Dr. Nahid Zarifsanaiey Associate Professor in e-Learning at the Virtual School, Comprehensive Center of Excellence for e-Learning in Medical Sciences at Shiraz University of Medical Sciences, Shiraz, Iran, and she is also an Academic Fellow at Department of Medical Education, Virtual University of Medical Sciences, Iran.

Dr. Mohammad Hossein Taghrir is a general physician who graduated from Shiraz University of Medical Sciences, Iran. He is a young researcher and currently working as a research assistant at Trauma Research Center, Shahid Rajaee (Emtiaz) Trauma Hospital, Shiraz University of Medical Sciences, Shiraz, Iran. He is passionate about medical and surgical education and also digital health and digital surgery. He has published papers in the fields of public health and surgery. More details can be found at: https://www.researchgate.net/profile/Mohammad-Hossein-Taghrir

Sima Roushenas is a medical student at Shiraz Medical School, Shiraz, Iran Her preference in research is mentorship in medical education.

Dr. Seyed Mehdi Panahandeh is a general physician who graduated from Shiraz University of Medical Sciences, Iran. He is passionate about oncology, internal medicine, and medical education. Also, he is co-founder of the mentorship program in Shiraz Medical School.

Dr. Hossein Abdolrahimzadeh-fard is an assistant professor of general surgery and trauma fellowship in Shiraz Medical school. Shiraz, Iran.

Dr. Zahra Shayan is an associate professor in the department of biostatistics, School of medicine, Shiraz University of Medical Sciences, Shiraz, Iran.

Shahin Kavousi is an MD/MPH candidate of the school of medicine, The shiraz university of medical sciences. His research interests include clinical problem solving, oncology, and public health. He has completed all of the MD/MPH degree requirements except for the dissertation.

Professor Shahram Paydar M.D.M.S. (medical education) is a full professor of General Surgery and trauma fellowship in Shiraz Medical school. Shiraz, Iran. $\mathrm{He}$ is an expert in surgical education, mentorship, clinical trials, and artificial intelligence applications in surgery.

\section{Introduction}

The education of general surgery residents is complicated. There are many expertise areas as a general surgeon, such as trauma which is considered a primary content area of general surgery education by the American Board of Surgery and other related committees (Musonza, Todd, Scott, Davis, \& Potts, 2019). This subject might be more complicated, considering the residents' suboptimal training because of duty hour restrictions (Kairys, DiMuzio, Crawford, Grabo, \& Yeo, 2009).

Trauma accounts for 20 percent of the global burden of diseases (World Health Organization, 2008). According to statistics, the trauma incidence rate is higher than the cumulative numbers of HIV, tuberculosis, and malaria each year (Mathers, 2008). This fact requires the immediate attention of surgical curriculum planners, mainly in the developing world, where 5-6 percent of mortalities are rooted in trauma occasions (Girgis 
\& Miller, 2018). In the Emergency Room (ER), the patients' critical condition necessitates an emergent patient approach, obtaining a proper history and physical examination, precisely ordering first-line lab data, and starting management plans. Clinical management of trauma victims is a matter of golden seconds/minutes (Paydar \& Akbarialiabad, 2020). In simple words, trauma is a surgical field where seconds matter and not minutes (Aggarwal et al., 2010).

Evidence shows that following the restriction in duty hours of residents and progression of subspecialty care, trauma training as one of the central core components of the general surgery curriculum has been markedly affected (Kuhls, Risucci, Bowyer, \& Luchette, 2013). This requires adopting novel educational methodologies to enhance learning and compensate for the deficiencies of academic programs.

Moreover, the traditional concept of surgical education where the training occurs merely in the operation room context is questionable, as the surgical education has moved forward to enhance efficacy and decrease the risks (Kuhls et al., 2013). Also, residency training differs from other types of training. The pedagogical approach is a traditional education in which students learn, and teachers teach (Chacko, 2018). On the other side, in an andragogical approach, the mentor/teacher merely facilitates learning. This would promote self-directed, problem-oriented, and learner-centered learning. With such an approach, the role of didactic lectures is blurred, and more focus is on other types of learning, such as problem-based learning (PBL) (Amin \& Khoo, 2003).

As a self-directed approach, flipped learning is composed of e-learning and faceto-face interactions. In this method, educational materials are provided to students outside the classroom through different technologies and modalities such as podcasts, video clips, multimedia, books, etc. Besides, face-to-face interaction focuses on interactive learning activities such as group discussion and questions and answers (Hew \& Lo, 2018).

In this respect, while flipped learning has provided many learning benefits and opportunities for learners, it has also encountered challenges. A major challenge is the effective design of educational content and strategies. Combining active learning methods such as case-based learning with appropriate educational content increases the effectiveness of education. Notably, case-based learning is a teaching method developed around a case (Ali et al., 2018). Accordingly, it is possible to make mistakes and investigate the consequences in a safe environment, ultimately reducing the risk of medical errors in real situations (Nielsen, 2016).

Even though there is increasing interest regarding this subject in medical education (Hew \& Lo, 2018), little has been published concerning flipped learning in the medical curriculum, precisely focusing on the post-graduate curriculum (F. Chen, Lui, \& Martinelli, 2017). In the current study, we aimed to investigate the applicability of flipped learning in trauma education among junior general surgery residents in Shiraz medical school, Iran. To the best of our knowledge, this is the first report concerning the application of flipped learning in the trauma rotation of general surgery residents. We sought to answers four research questions: (I) Can flipped learning foster knowledge acquisition? (II) Can flipped learning lead to the encouragement of knowledge retention in trauma rotation? (III) How much our residents used each material provided? (IV) Was the overall program satisfactory to participants? 


\section{Literature review}

The integration of any new educational strategy necessitates proper recognition of the pros and cons of the program (Jayakumar, Brunckhorst, Dasgupta, Khan, \& Ahmed, 2015; Kew \& Tasir, 2021). One novel educational method that integrates the traditional "inclassroom" education with e-learning is blended learning (Grasl et al., 2012). This method is considered a bridge from the conventional, teacher-dominated, and face-to-face lectures/discussions to fully web-based education (Back et al., 2014; Negahban \& Zarifsanaiey, 2020). Fig. 1 presents the pros and cons of integrating e-learning in educational practice.

\begin{tabular}{|l|l|}
\hline \multicolumn{1}{|c|}{ Advantages } & \multicolumn{1}{c|}{ Disadvantages } \\
\cline { 2 - 2 } - Ease of access & $\begin{array}{l}\text { - Dependent on internet speed } \\
\text { - Flexibility of learning } \\
\text { - Easily updatable } \\
\text { - Presented with multimedia }\end{array}$ \\
- Economies of scale & $\begin{array}{l}\text { - Progh initial cost } \\
\text { - Personalized learning }\end{array}$ \\
\hline
\end{tabular}

Fig.1. A schematic list of the advantages and disadvantages of e-learning

Blended learning, especially flipped classrooms, arose from high schools and undergraduates of non-medical fields. However, this method progressed rapidly in many areas, including medicine (Alberts, 2012). In this method, teachers provide the curriculum content in a balanced, targeted way. Some materials are provided in the form of movies, while others are offered in podcasts or books. Additionally, the students attend the case-based, teacher-facilitated discussions after reviewing and processing resources (F. Chen, Lui, \& Martinelli, 2017).

This method was first used by Jonathan Bergmann and Aaron Sams in 2007 (Bergmann \& Sams, 2007) when they decided to provide audio narrated PowerPoints for absent students in a chemistry course (McDonald \& Smith, 2013; Tan, Brainard, \& Larkin, 2015). They defined this kind of learning as "what traditionally done in class now is done in the homes, and what is traditionally done as homework now is done in the class" (McDonald \& Smith, 2013). In this approach, as all students are, at least, familiar with the concept of the topic, the class time would be more beneficial to both high-ranked and mediocre ones (Prober \& Heath, 2012). Also, as it is learner-based and discussionbased, it would promote higher cognitive functions such as analysis and critical thinking (Anderson \& Sosniak, 1994).

Flipped learning has emerged in residency programs to address the busy schedules of faculties and residents and increase effectiveness considering the restricted duty hours (Girgis \& Miller, 2018). This method is considered highly effective for junior residents because they are less experienced, quickly feel overwhelmed, and have high working stress, resulting in early burnout (Ebrahimi \& Kargar, 2018). In designing a flipped curriculum for general surgery residents, teachers and curriculum planners should develop the curriculum in a time-effective and flexible manner that does not require onsite attending of classes (Wittich et al., 2018). Since the COVID-19 pandemic has disrupted in-person classrooms, electronic learning (and blended learning) is currently highlighted more (Akbarialiabad, Fard, et al., 2020; Akbarialiabad, Kavousi, Ghahramani, 
Bastani, \& Ghahramani, 2020; Dhawan, 2020; Moszkowicz, Duboc, Dubertret, Roux, \& Bretagnol, 2020).

A large number of studies have been conducted to investigate the effectiveness of flipped learning and have found this approach greatly effective in enhancing knowledge, skill, motivation, and satisfaction among students (K. S. Chen et al., 2018; Riddell et al., 2017). Moreover, Graham et al. revealed that flipped learning is more effective than conventional learning in knowledge acquisition among internal medicine residents (Graham, Cohen, Reynolds, \& Huang, 2019). In a study considering undergraduate medical students, flipped learning was associated with higher satisfaction and engagement with teaching but not with the improvement of final scores (Chowdhury et al., 2019). Regarding dental education, a systematic review showed that flipped learning is an effective method of education and time flexibility was a major asset in this method, making students follow the learning materials with their own pace (Gianoni-Capenakas, Lagravere, Pacheco-Pereira, \& Yacyshyn, 2019). In the case of nursing education, various studies showed the effectiveness of flipped learning in academic progress (Cho \& Kim, 2019; Gu \& Sok, 2020; Im \& Jang, 2019; Lee \& Park, 2018), and a meta-analysis confirmed this effectiveness (Li et al., 2020).

In light of these pieces of evidence, one can conclude that there is an increasing interest in implementing flipped learning in medical education curricula, and its encouraging impacts on academic improvements of students are not negligible. Since there is a scarcity of evidence in post-graduate and residency programs, we decided to investigate the effect of flipped learning on the first-year general surgery residents serving in trauma rotation. The findings can help convince medical education officials to integrate such learning methods into the teaching curricula.

\section{Methods}

The present mixed-method study (quasi-experiment \& content analysis) with a one-group pre-test post-test design was conducted to determine the effect of a flipped learning program based on clinical decision-making and problem-solving ability of general surgery residents of Shiraz medical school, Shiraz, Iran, concerning the primary trauma survey. The census method of sampling was used, and participants were compared with their pre-test, early post-test, and late post-test outcomes.

\subsection{Participants}

First-year general surgery residents with Doctor of Medicine (MD) degree who took the trauma surgery rotation were eligible. Students who had no desire to complete the questionnaires and have had previous flipped learning experiences were excluded.

Fifteen participants were eligible at the time of the study (April -May 2019), nine were male, and six were female. All of them were invited to participate in the study. None of them met the exclusion criteria.

The Ethics committee approved the study of Shiraz University of Medical Sciences (IR.SUMS.REC.1399.721). After explaining the study's aims and method, all residents agreed to participate in our study. In this step, informed written consent was obtained from the participants. We assured confidentiality of information. 


\subsection{Learning materials}

The study was designed with a collaboration between "Shiraz Trauma Hospital" and "Educational Development Center" of Shiraz University of Medical Sciences. The educational materials were composed of videos, rapid review podcasts, and books. The educational content was selected from two specific references: Advanced Trauma Life Support (ATLS), 10th Edition, Student Course Manual 2018, published by the American College of Surgeons (ACS), ATLS hereafter; and the trauma chapter (7th chapter) of Schwartz's Principles of Surgery. 11th edition, 2019, McGraw-Hill publication.

The multimedia content (video and podcasts) was prepared based on our most extensive consultation of two separate expert panels composing four trauma surgeons and five medical educationists, mainly according to the content of the ATLS. Curriculum and educational materials were prepared in June and August 2019. The recorded materials were 17 hours of video and five rapid review podcasts. The video sessions, using real-life scenarios, were comprise of 13 titles (each approximately 60 minutes and a maximum of 1.5 hours). The titles of the visual media are available in Table 1 . The podcasts were about 30 minutes and rapidly reviewed the "must-know" points or videos.

Table 1

The learning topics

\begin{tabular}{lll}
\hline Initial assessment and management & Airway and ventilatory management & Shock \\
\hline Thoracic trauma & Abdominal and pelvic trauma & Head trauma \\
Spine and spinal cord trauma & Musculoskeletal trauma & Thermal injuries \\
Pediatric trauma & Geriatric trauma & $\begin{array}{l}\text { Trauma in pregnancy and intimate } \\
\text { partner violence }\end{array}$ \\
Transfer to definite care & & \\
\hline
\end{tabular}

There was a one-session class reviewing all the essentials of the course in a casebased manner. It lasted for 2.5 hours and was held interactively. Clinical attendees discussed the cases separately and highlighted the must-know points of the course.

The implementation of the flipped education program and evaluation phase lasted from September to November 2019. In early September 2019, a pre-test examination was held to assess the residents' baseline knowledge or problem-solving ability regarding the primary trauma survey. After that, all participants received educational movies, podcasts, and books on the primary trauma survey. Four weeks later, in early October, a case-based discussion was held for residents in a 2.5 -hour class discussion. In the discussion, the surgical attendees reviewed the topics using case-based teaching and interactive lecture. An early post-test was performed after the case-based discussion to assess the program's early effectiveness in clinical problem-solving. One month later (early November), all the residents participated in a delayed post-test examination evaluating the impact of the whole program on knowledge retention of the contents. In order to assess the higher level of cognition, pre-test, early post-test, and the late post-test were composed of 20 comparable clinical scenarios to evaluate clinical decision making and problem-solving capabilities (Armstrong, 2016). In mid-November 2019, a semi-structured phone interview, using a five-point Likert scale, was conducted by an external expert. Each interview lasted around 20 minutes. The interviews were then transcribed and analyzed using qualitative content analysis. 


\subsection{Instruments}

\subsubsection{Problem-solving test}

In order to investigate the residents' problem-solving ability, multiple-choice questions (MCQs) composed of 20 clinical scenarios on the primary trauma survey were employed. Each correct answer equaled one positive score for the responder with a total score of 20 . The face and content validities were confirmed by four content experts of the "Educational Developmental Center" of Shiraz University of Medical Sciences. The reliability of the tests was approved with a correlation coefficient of $0.8,0.75$, and 0.78 using test-retest reliability assessment.

\subsubsection{A semi-structured interview}

The content validity of the structured interview form was validated by four content experts of the "Educational Developmental Center" of Shiraz University of Medical Sciences. The forms had five main sections with related subsections. The residents were asked to rate the whole program, how much they used each material, the benefits of each material in knowledge acquisition/retention, and confidence promotion in decision making. The final item was an open question to evaluate the benefits/drawbacks of this model. Phone interviews were transcribed verbatim and studied by the first and corresponding authors and analyzed with qualitative content analysis. The appropriate text fragments were chosen. Following that, the fragments were labelled and sorted. At the final step, utilizing these fragments, central themes were extracted. In cases where these authors were not in complete agreement, the final decision was made by the second author. Finally, eight main themes were extracted, which are available in Table 3.

\subsection{Data analysis}

Data analysis was carried out by SPSS statistical software (version 18, Chicago, IL, USA). The Mann-Whitney test, Spearman's rho, and paired T-test were used where applicable. $\mathrm{P}$ value $<0.05$ was considered as the significance level.

\section{Results}

In this study, all the $15(100 \%)$ junior general surgery residents completed the research process. In terms of gender and age, $60 \%$ were male, and $40 \%$ were female, with a mean age of $29 \pm 3$ years.

The first objective of the present study was to investigate the attitude of junior general surgery residents toward flipped learning. Another objective of the research was to determine the effect of flipped learning on gaining and retaining problem-solving ability in primary trauma surveys. In order to investigate the problem-solving ability, 20 multiple-choice clinical scenarios were used to assess the competency of residents' problem-solving in the pre-test, the early, and the late post-tests.

As shown in Table 2, the results showed that in the quantitative phase, there was a significant difference between pre-test $(\mathrm{M}=10.733, \mathrm{SD}=2.25)$ and the early post-test $(\mathrm{M}=12.8, \mathrm{SD}=1.82)(p=0.004)$, and between pre-test $(\mathrm{M}=10.733, \mathrm{SD}=2.25)$ and the late post-test $(\mathrm{M}=13.267, \mathrm{SD}=1.53)(p=0.002)$. Interestingly, there was no significant difference between early post-tests and late post-tests $(p=0.404)$. 
Table 2

Problem-solving scores of the intervention group

\begin{tabular}{llll}
\hline Test & $\mathrm{M}$ and SD & Method & Difference \\
\hline Pre-test & $\mathrm{M}=10.73, \mathrm{SD}=2.25$ & Paired T-test & Significant \\
Early- post-test & $\mathrm{M}=12.8, \mathrm{SD}=1.82)$ & & $(p=0.004)$ \\
Pre-test & $\mathrm{M}=10.73, \mathrm{SD}=2.25$ & Paired T-test & Significant \\
Late post-test & $\mathrm{M}=13.26, \mathrm{SD}=1.53$ & & $(p=0.002)$ \\
Early post-test & $\mathrm{M}=12.8, \mathrm{SD}=1.82$ & Paired T-test & Not significant \\
Late-post test & $\mathrm{M}=13.26, \mathrm{SD}=1.53$ & & $(p=0.404)$ \\
\hline Note. $\mathrm{M}=$ mean, $\mathrm{SD}=$ standard deviation & &
\end{tabular}

Also, we correlated the test scores with the residents' gender using the MannWhitney test. There was no correlation between the test scores and gender (Table 3).

Table 3

Comparison of the result in test scores between males and females

\begin{tabular}{lllllll}
\hline & Sex & N & Mean & SD & $p$ & Correlation \\
\hline \multirow{2}{*}{ pre-test } & female & 6 & 11.33 & 2.33 & 0.47 & Not significant \\
& male & 9 & 10.33 & 2.23 & & \\
Early post-test & female & 6 & 13.50 & 0.83 & 0.21 & Not significant \\
& male & 9 & 12.33 & 2.17 & & \\
Late post-test & female & 6 & 13.50 & 1.22 & 0.79 & Not significant \\
& male & 9 & 13.11 & 1.76 & & \\
\hline
\end{tabular}

The results of the test scores are available in the above tables. In each test, the mean and standard deviation of scores is provided. Performing the Mann-Whitney test, we found no correlation between the results and genders.

In the qualitative phase, an external expert was called and interviewed the residents using a semi-structured form. The questions were mainly focused on the quantitative use of the materials, the overall gain of each material, promotion of theoretical knowledge, and bedside decision making. Moreover, they were asked to rate the program with a score of 1 to 5 . The data are summarized in Table 4.

It is shown in 4 that the residents were satisfied with the program's overall usefulness (overall score 4/5). The average rate of video usage was $1.93 / 5$. The video users believed that they promoted theoretical knowledge (3.33/5) and enhanced bedside decision-making (3.67/5). Regarding the podcasts, the mean employment of the podcasts among the residents was $5 / 5$. The perceived gain from the podcasts regarding the knowledge and confidence in the management of the patients in real life was shown to be $4.33 / 5$ and 3.6/5, respectively. In terms of the paper materials (books), the quantitative use of the books was $2.2 / 5$. Besides, we found that the impact of the books in promoting theoretical knowledge was $4.13 / 5$, while the impact of the books on the clinical judgment was 3.38/5. Concerning the case-based discussion session, all the residents attended that particular session $(5 / 5)$. They believed that the efficacy of that case-based discussion on their knowledge and bedside judgment was 3.93 and 4.4 out of 5 , respectively. Less use 
of the videos may be attributed to their long duration, which needs to be considered in further application of this method.

Table 4

Results from the semi-structured interview

The overall score of the whole program

Efficacy of the case-based discussion in increasing the confidence in bedside decision making

Efficacy of the case-based discussion in promoting theoretical knowledge

Efficacy of the books in promoting increasing the confidence in bedside decision making

Efficacy of the books in promoting theoretical knowledge (out of 5)

Quantitative use of the books

Efficacy of the podcasts in increasing the confidence in bedside decision making

Efficacy of the podcasts in promoting theoretical knowledge

Quantitative use of the podcasts

Efficacy of the videos in increasing the confidence in bedside decision making

Efficacy of the videos in promoting theoretical knowledge

Quantitative use of the videos

Attendance in the case-based discussion

All attended

As summarized in Table 5, the final question in our phone interview was an open question. We asked the residents to mention any other required points to improve the program. After transcribing all the 15 interviews, the subjects were categorized into eight cardinal themes. Seven residents believed that the course was highly beneficial, and they suggested that this course be held every 2-3 months in a progressive mode. Six residents admired the case-based interactive nature of the discussion in helping them to overcome stress in real-life situations. However, one resident recommended that the session be over 2.5 hours to cover all the issues. Five residents suggested that the first month of the residency program be devoted to professionally prepare them to deal with patients, while two residents disagreed with this. The two residents held that education happens in real encounters of patients, and they preferred to have ongoing education while managing patients in clinical wards. In our qualitative study, five residents believed that podcasts are a great asset for learning, and they present a recapitulation of the essentials. They believed that they could listen to these audios while waiting for patients or going from one ward to another ward or in their leisure time. One resident suggested that the casebased discussion be held with the presence of senior residents, which helps the junior residents use their experiences. The company of the seniors could also facilitate the establishment of a peer mentorship between junior residents and the seniors (Table 5). 
Table 5

The residents' attitude and suggestion toward the program

\begin{tabular}{|c|c|}
\hline Statement & Resident number \\
\hline $\begin{array}{l}\text { Regarding the timing, I suppose that the first month of our training program should } \\
\text { be a pure observership with no clinical posting. In that time, we should learn/review } \\
\text { all "must-know" points and then attend the wards. This will make us more confident } \\
\text { when dealing with the patients }\end{array}$ & $3,4,7,11,14$ \\
\hline $\begin{array}{l}\text { I suppose that we should not have a pure observership month filled with classes } \\
\text { because we will notice the importance of the knowledge if we see their practicality } \\
\text { in the field }\end{array}$ & 12,13 \\
\hline $\begin{array}{l}\text { The case-based discussion was done in interactive mode and was helpful to decrease } \\
\text { our stress of patient contact }\end{array}$ & $2,4,5,9,11,13,15$ \\
\hline $\begin{array}{l}\text { This method should be held every } 2-3 \text { months. The course should be progressive, } \\
\text { starting with a primary trauma survey and going forward to more advanced care. }\end{array}$ & $1,2,6,8,10,11,15$ \\
\hline $\begin{array}{l}\text { Podcasts were highly concise and too beneficial as we can review them when/where } \\
\text { ever needed. }\end{array}$ & $3,10,11,12,14$ \\
\hline $\begin{array}{l}\text { Videos were comprehensive and excellent for learning, but the duration of them } \\
\text { should be more limited }\end{array}$ & 4 \\
\hline $\begin{array}{l}\text { The presence of senior residents as teacher assistants in CBD sessions may help us } \\
\text { to have their experience as well and foster their mentoring role }\end{array}$ & 8 \\
\hline The 2.5-hour class was not enough to review all essentials & 3 \\
\hline
\end{tabular}

\section{Discussion}

The study results showed that intervention improved the knowledge level at both followups. This finding is in line with other studies, which showed the effectiveness of flipped learning in terms of knowledge acquisition in medical education (Akbarialiabad, Fard, et al., 2020; Gianoni-Capenakas, Lagravere, Pacheco-Pereira, \& Yacyshyn, 2019; Heitz, Prusakowski, Willis, \& Franck, 2015; Presti, 2016; Rose et al., 2016; Tan et al., 2015; Tolks et al., 2016). The results reveal that flipped learning helps encourage deep and active learning (Danker, 2015; Lewis, Chen, \& Relan, 2018) and school achievement (Liebert, Lin, Mazer, Bereknyei, \& Lau, 2016). The flipped learning is increasingly gaining a reputation as a fascinating and successful instructional methodology. Evidence is still scarce in the utilization of flipped learning in medical education and especially surgical education and the field of trauma. This is the first paper which investigates the applicability of the flipped learning in the trauma for general surgery residents.

In our investigation, knowledge retention was confirmed by a lack of difference between the early post-test and the late post-test. We believe that this occurred probably because the provided materials were prepared according to daily encountered scenarios in our local trauma care center. As in our study, several surveys have proposed that this method promotes the test scores as compared with traditional methods (Wittich et al., 2018; Wolff, Wagner, Poznanski, Schiller, \& Santen, 2015). 
Similar to other studies, this study also showed a high level of satisfaction among participants. In a study by Tan et al., $96 \%$ of the respondents were satisfied with their flipped curriculum in emergency medicine and believed that is superior to traditional curricula. The participants believe that having the resources before attending the class encourages learning and is considered a motivator (Tan et al., 2015).

Moreover, in a cohort study, it was shown that besides experiencing a higher level of satisfaction, with flipped surgical curriculum, medical clerks were more interested in pursuing surgery as the prospective professional field. (Liebert, Lin, et al., 2016). Another survey conducted by Liebert et al. in a surgery clerkship showed that about $90 \%$ of students rated their flipped learning curriculum excellent or outstanding. Moreover, $84 \%$ of the clerks believed that other clerkships should adopt a flipped-based curriculum (Liebert, Mazer, Merrell, Lin, \& Lau, 2016).

Advocating self-directed, active, and efficient learning are chief objectives for educational interventions for fostering adult learning (andragogy) (Kan et al., 2015; Kaufman, 2003; Tan et al., 2015). Other studies have shown the effects of flipped learning on metacognitive skills (Yilmaz \& Baydas, 2017). In this method, the learners have the authority to manage resources, pace, place, and time, which makes them capable of self-regulation and performance (Lewis et al., 2018; Shyr \& Chen, 2018; Tan et al., 2015). Our study found that the residents were delighted with their curriculum and uniquely interactive case-based discussion. They found it was constructive in relieving stress in real patient encounters. Another study confirms these findings as the participants believed that flipped learning and case-based discussion sessions could lead to a higher level of cognitive functions such as analysis and synthesis of knowledge (Moffett, 2015; Wood, 2003). Several papers concerning flipped learning support the effectiveness of case-based learning in these settings (Prober \& Heath, 2012; Sharma, Lau, Doherty, \& Harbutt, 2015; Srinivasan, Wilkes, Stevenson, Nguyen, \& Slavin, 2007). Cases-based learning will foster higher-order educational objectives in bloom's taxonomy and cognitive ladder. We believe that this method is helpful as it encourages constructivism in medicine. Studies suggest that flipped learning helps learners build knowledge based on the pre-class materials, the case-based discussion, and their clinical experiences (McDonald \& Smith, 2013; Prunuske, Batzli, Howell, \& Miller, 2012).

One of our residents believed that the videos were lengthy but comprehensive. The videos lasted 17 hours on 13 subjects (with an average of 1 hour for each topic and a max of 1.5 hours). We believed, to be effective, all future video sessions should be limited to a maximum of 1 hour. This finding is consistent with other studies. The authors finally decided to trim the video materials to be less than 60 minutes, based on feedback they received at the end of the educational program (Kurup \& Hersey, 2013; Sharma et al., 2015). Some experts believe that long videos can quickly fill the working memory, which has minimal capacity. However, shorter videos make the individual actively process ongoing information (Brame, 2015).

Also, we noticed that our participants tended to use podcasts more than other materials due possible to the remarkably shorter nature of podcasts, making them appropriate at any time and place. Our findings are similar to another study in which synopsized materials such as podcasts were more favorable to be used by the participants (Tan et al., 2015).

Our residents believed that videos and books help more to foster knowledge. The case-based discussion (CBD) makes them more confident in dealing with patients (Table $2,3)$. It may be implied that the high rate of the CBD is potentially due to the pre-class preparation of the participants, which encourages learning (Hew \& Lo, 2018), being 
evidence for flipped learning. We noticed that none of the materials result in better results per se. Generally, they led to a significant difference in the efficacy of this method (Table 2 ). We believe the ideal framework should entail all of the materials and multiple strategies to cover numerous learning styles that meet the educational objectives of the program (Kannan \& Kurup, 2012).

The high acceptability of flipped learning in this study revealed the efficacy and utility of this surgical field method, especially in trauma. In surgical residency programs, different schedules, limited educational time, and immediate need for the care of trauma victims threaten proper, uniform, and synchronized education of residents. Flipping the education will help the residents have an invaluable learning source, which is always available to them. This method also saves the time of instructors to repeat basic facts. It helps the surgical team focus on more advanced point-of-care teachings, which may be neglected due to time constraints (Tan et al., 2015).

\section{Conclusion}

We concluded that flipped learning is invaluable where the pace of attaining certain competencies matters like trauma. In our study, participants had a high level of satisfaction. The early and late post-tests were significantly higher in comparison to the pre-test, which was in favor of the efficacy of flipped learning in knowledge acquisition and retention.

Although our general surgery program is one of the most significant programs in Iran, this study was in a single school with a limited sample size. The small number of participants may mitigate biases, but further investigations are required. Also, the lack of a control group to compare the effectiveness was another limitation of this study.

Further cohort and randomized educational intervention trials with larger samples are required to investigate the applicability of flipped learning in post-graduates, mainly in general surgery and traumatology. Future studies might focus on mediator factors that could interfere with educational outcomes encompassing enthusiasm and motivation to learning, job satisfaction, job performance, job burnout, etc. The COVID-19 pandemic has disturbed regular modes of medical education. The promising effects of flipped learning in medical education highlight the possibility of its usage in medical curricula to encounter inevitable scars of the current pandemic on medical education.

\section{Author Statement}

The authors declare that there is no conflict of interest.

\section{Acknowledgements}

The authors of this study appreciate Professor Ghaffar Abbasi Goidargh, Dr.Seyed Reza sadrosadati, Dr. Seyed Hossein Hosseini, Dr. Mojtaba Zare, and Dr.Ali Alinejad for the native language editing of the manuscript. 


\section{ORCIID}

Hossein Akbarialiabad (10) https://orcid.org/0000-0003-2018-6378

Nahid Zarifsanaiey (iD https://orcid.org/0000-0002-1297-8271

Mohammad Hossein Taghrir (10) https://orcid.org/0000-0003-2293-0383

Sima Roushenas (1D) https://orcid.org/0000-0001-9403-5201

Mehdi Panahandeh (iD) https://orcid.org/0000-0002-6168-3760

Hossein Abdolrahimzadeh-fard (iD https://orcid.org/0000-0003-1225-9186

Zahra Shayan (10 https://orcid.org/0000-0002-3172-6862

Shahin Kavousi (iD https://orcid.org/0000-0001-9587-6803

Shahram Paydar (iD https://orcid.org/0000-0002-6980-2576

\section{References}

Aggarwal, R., Mytton, O. T., Derbrew, M., Hananel, D., Heydenburg, M., Issenberg, B., . . Reznick, R. (2010). Training and simulation for patient safety. BMJ Quality \& Safety, 19(Suppl 2), i34-i43.

Akbarialiabad, H., Fard, H. A., Abbasi, H. R., Bolandparvaz, S., Mohseni, S., Mehrnous, V., . . Trauma. (2020). Our experience of trauma management during novel coronovirus 2019 (COVID-19) pandemic in a busy trauma center in Southern Iran. Bulletin of Emergency \& Trauma, 8(3), 199-201.

Akbarialiabad, H., Kavousi, S., Ghahramani, A., Bastani, B., \& Ghahramani, N. (2020). COVID-19 and maintenance hemodialysis: A systematic scoping review of practice guidelines. BMC Nephrology, 21: 470. doi: 10.1186/s12882-020-02143-7

Alberts, B. (2012). Failure of skin-deep learning. Science, 338(6112), 1263-1263.

Ali, M., Han, S. C., Bilal, H. S. M., Lee, S., Kang, M. J. Y., Kang, B. H., . . Amin, M. B. (2018). iCBLS: An interactive case-based learning system for medical education. International Journal of Medical Informatics, 109, 55-69.

Amin, Z., \& Khoo, H. E. (2003). Basics in medical education. Hackensack, NJ: World Scientific.

Anderson, L. W., \& Sosniak, L. A. (1994). Bloom's taxonomy. The University of Chicago Press.

Armstrong, P. (2016). Bloom's taxonomy. Vanderbilt University Center for Teaching, USA.

Back, D. A., Haberstroh, N., Sostmann, K., Schmidmaier, G., Putzier, M., Perka, C., \& Hoff, E. (2014). High efficacy and students' satisfaction after voluntary vs mandatory use of an e-learning program in traumatology and orthopedics-A follow-up study. Journal of Surgical Education, 71(3), 353-359.

Bergmann, J., \& Sams, A. (2007). The flipped classroom is born. Retrieved from https://www.youtube.com/watch?v=v-y9vR7YTak

Brame, C. J. (2015). Effective educational videos. Vanderbilt University Center for Teaching, USA.

Chacko, T. V. (2018). Emerging pedagogies for effective adult learning: From andragogy to heutagogy. Archives of Medicine and Health Sciences, 6(2), 278-283.

Chen, F., Lui, A. M., \& Martinelli, S. M. (2017). A systematic review of the effectiveness of flipped classrooms in medical education. Medical Education, 51(6), 585-597.

Chen, K. S., Monrouxe, L., Lu, Y. H., Jenq, C. C., Chang, Y. J., Chang, Y. C., \& Chai, P. 
Y. C. (2018). Academic outcomes of flipped classroom learning: A meta-analysis. Medical Education, 52(9), 910-924.

Cho, M. K., \& Kim, M. Y. (2019). Outcomes and influential factors applying flipped learning methods in a clinical adult nursing practicum. International Journal of Nursing Practice, 25(2): e12724. doi:10.1111/ijn.12724

Chowdhury, T. A., Khan, H., Druce, M. R., Drake, W. M., Rajakariar, R., Thuraisingham, R., . . . Alstead, E. M. (2019). Flipped learning: Turning medical education upside down. Future Healthcare Journal, 6(3), 192-195. doi: 10.7861/fhj.2018-0017

Danker, B. (2015). Using flipped classroom approach to explore deep learning in large classrooms. IAFOR Journal of Education, 3(1), 171-186.

Dhawan, S. (2020). Online learning: A panacea in the time of COVID-19 crisis. Journal of Educational Technology Systems, 49(1), 5-22.

Ebrahimi, S., \& Kargar, Z. (2018). Occupational stress among medical residents in educational hospitals. Annals of Occupational and Environmental Medicine, 30: 51.

Gianoni-Capenakas, S., Lagravere, M., Pacheco-Pereira, C., \& Yacyshyn, J. (2019). Effectiveness and perceptions of flipped learning model in dental education: A systematic review. Journal of Dental Education, 83(8), 935-945.

Girgis, F., \& Miller, J. P. (2018). Implementation of a "flipped classroom" for neurosurgery resident education. Canadian Journal of Neurological Sciences, 45(1), 76-82.

Graham, K. L., Cohen, A., Reynolds, E. E., \& Huang, G. C. (2019). Effect of a flipped classroom on knowledge acquisition and retention in an internal medicine residency program. Journal of Graduate Medical Education, 11(1), 92-97.

Grasl, M. C., Pokieser, P., Gleiss, A., Brandstaetter, J., Sigmund, T., Erovic, B. M., \& Fischer, M. R. (2012). A new blended learning concept for medical students in otolaryngology. Archives of Otolaryngology-Head \& Neck Surgery, 138(4), 358-366.

Gu, M., \& Sok, S. R. (2020). Effects of simulation practicum using flipped learning for Korean nursing students. International Journal of Environmental Research and Public Health, 17(18): 6829. doi: 10.3390/ijerph17186829

Heitz, C., Prusakowski, M., Willis, G., \& Franck, C. (2015). Does the concept of the "flipped classroom" extend to the emergency medicine clinical clerkship? Western Journal of Emergency Medicine, 16(6), 851-855.

Hew, K. F., \& Lo, C. K. (2018). Flipped classroom improves student learning in health professions education: A meta-analysis. BMC Medical Education, 18: 38.

Im, S., \& Jang, S. J. (2019). Effects of a clinical practicum using flipped learning among undergraduate nursing students. Journal of Nursing Education, 58(6), 354-356.

Jayakumar, N., Brunckhorst, O., Dasgupta, P., Khan, M. S., \& Ahmed, K. (2015). eLearning in surgical education: A systematic review. Journal of Surgical Education, 72(6), 1145-1157.

Kairys, J. C., DiMuzio, P. J., Crawford, A. G., Grabo, D. J., \& Yeo, C. J. (2009). Changes in operative case experience for general surgery residents: Has the 80-hour work week decreased residents' operative experience? Advances in Surgery, 43(1), 73-90.

Kan, C., Harrison, S., Robinson, B., Barnes, A., Chisolm, M. S., \& Conlan, L. (2015). How we developed a trainee-led book group as a supplementary education tool for psychiatric training in the 21st century. Medical Teacher, 37(9), 803-806.

Kannan, J., \& Kurup, V. (2012). Blended learning in anesthesia education: Current state and future model. Current Opinion in Anesthesiology, 25(6), 692-698.

Kaufman, D. M. (2003). Applying educational theory in practice. BMJ, 326(7382), 213216.

Kew, S. N., \& Tasir, Z. (2021). Analysing students' cognitive engagement in e-learning 
discussion forums through content analysis. Knowledge Management \& E-Learning, 13(1), 39-57.

Kuhls, D. A., Risucci, D. A., Bowyer, M. W., \& Luchette, F. A. (2013). Advanced surgical skills for exposure in trauma: A new surgical skills cadaver course for surgery residents and fellows. Journal of Trauma and Acute Care Surgery, 74(2), $664-670$.

Kurup, V., \& Hersey, D. (2013). The changing landscape of anesthesia education: Is flipped classroom the answer? Current Opinion in Anesthesiology, 26(6), 726-731.

Lee, M. K., \& Park, B. K. (2018). Effects of flipped learning using online materials in a surgical nursing practicum: A pilot stratified group-randomized trial. Healthcare Informatics Research, 24(1), 69-78. doi: 10.4258/hir.2018.24.1.69

Lewis, C. E., Chen, D. C., \& Relan, A. (2018). Implementation of a flipped classroom approach to promote active learning in the third-year surgery clerkship. The American Journal of Surgery, 215(2), 298-303.

Li, B. Z., Cao, N. W., Ren, C. X., Chu, X. J., Zhou, H. Y., \& Guo, B. (2020). Flipped classroom improves nursing students' theoretical learning in China: A meta-analysis. PLoS One, 15(8): e0237926. doi: 10.1371/journal.pone.0237926

Liebert, C. A., Lin, D. T., Mazer, L. M., Bereknyei, S., \& Lau, J. N. (2016). Effectiveness of the surgery core clerkship flipped classroom: A prospective cohort trial. The American Journal of Surgery, 211(2), 451-457.

Liebert, C. A., Mazer, L., Merrell, S. B., Lin, D. T., \& Lau, J. N. (2016). Student perceptions of a simulation-based flipped classroom for the surgery clerkship: A mixed-methods study. Surgery, 160(3), 591-598.

Mathers, C. (2008). The global burden of disease: 2004 update. World Health Organization.

McDonald, K., \& Smith, C. M. (2013). The flipped classroom for professional development: Part I. Benefits and strategies. The Journal of Continuing Education in Nursing, 44(10), 437-438.

Moffett, J. (2015). Twelve tips for "flipping" the classroom. Medical Teacher, 37(4), 331-336.

Moszkowicz, D., Duboc, H., Dubertret, C., Roux, D., \& Bretagnol, F. (2020). Daily medical education for confined students during COVID-19 pandemic: A simple videoconference solution. Clinical Anatomy, 33(6), 927-928.

Musonza, T., Todd, S. R., Scott, B., Davis, M. A., \& Potts, J. (2019). Trends in resident operative trauma: How to train future trauma surgeons? The American Journal of Surgery, 218(6), 1156-1161.

Negahban, M. B., \& Zarifsanaiey, N. (2020). Network analysis and scientific mapping of the e-learning literature from 1995 to 2018. Knowledge Management \& E-Learning, $12(3), 268-279$.

Nielsen, A. (2016). Concept-based learning in clinical experiences: Bringing theory to clinical education for deep learning. Journal of Nursing Education, 55(7), 365-371.

Paydar, S., \& Akbarialiabad, H. (2020). Utilizing novel assessment and instructional methodologies of trauma for residents; A case of blended learning in Shiraz Medical School. Bulletin of Emergency \& Trauma, 8(1), 1-3.

Presti, C. R. (2016). The flipped learning approach in nursing education: A literature review. Journal of Nursing Education, 55(5), 252-257.

Prober, C. G., \& Heath, C. (2012). Lecture halls without lectures-A proposal for medical education. The New England Journal of Medicine, 366(18), 1657-1659.

Prunuske, A. J., Batzli, J., Howell, E., \& Miller, S. (2012). Using online lectures to make time for active learning. Genetics, 192(1), 67-72.

Riddell, J., Jhun, P., Fung, C.-C., Comes, J., Sawtelle, S., Tabatabai, R., . . Swadron, S. P. (2017). Does the flipped classroom improve learning in graduate medical education? 
Journal of Graduate Medical Education, 9(4), 491-496.

Rose, E., Claudius, I., Tabatabai, R., Kearl, L., Behar, S., \& Jhun, P. (2016). The flipped classroom in emergency medicine using online videos with interpolated questions. The Journal of Emergency Medicine, 51(3), 284-291.

Sharma, N., Lau, C. S., Doherty, I., \& Harbutt, D. (2015). How we flipped the medical classroom. Medical Teacher, 37(4), 327-330.

Shyr, W. J., \& Chen, C. H. (2018). Designing a technology-enhanced flipped learning system to facilitate students' self-regulation and performance. Journal of Computer Assisted Learning, 34(1), 53-62.

Srinivasan, M., Wilkes, M., Stevenson, F., Nguyen, T., \& Slavin, S. (2007). Comparing problem-based learning with case-based learning: Effects of a major curricular shift at two institutions. Academic Medicine, 82(1), 74-82.

Tan, E., Brainard, A., \& Larkin, G. L. (2015). Acceptability of the flipped classroom approach for in-house teaching in emergency medicine. Emergency Medicine Australasia, 27(5), 453-459.

Tolks, D., Schäfer, C., Raupach, T., Kruse, L., Sarikas, A., Gerhardt-Szép, S., . . Hege, I. (2016). An introduction to the inverted/flipped classroom model in education and advanced training in medicine and in the healthcare professions. GMS Journal for Medical Education, 33(3): Doc46.

Wittich, C. M., Agrawal, A., Wang, A. T., Halvorsen, A. J., Mandrekar, J. N., Chaudhry, S., . . Beckman, T. J. (2018). Flipped classrooms in graduate medical education: A national survey of residency program directors. Academic Medicine, 93(3), 471-477.

Wolff, M., Wagner, M. J., Poznanski, S., Schiller, J., \& Santen, S. (2015). Not another boring lecture: Engaging learners with active learning techniques. The Journal of Emergency Medicine, 48(1), 85-93.

Wood, D. F. (2003). Problem based learning. BMJ, 326(7384), 328-330.

World Health Organization. (2008). The global burden of disease: 2004 update. World Health Organization.

Yilmaz, R. M., \& Baydas, O. (2017). An examination of undergraduates' metacognitive strategies in pre-class asynchronous activity in a flipped classroom. Educational Technology Research and Development, 65(6), 1547-1567. 